\title{
Developmental Competence of Buffalo Oocytes Cultured Under Different Oxygen Tensions after Selection with Brilliant Cresyl Blue
}

\author{
Dalia Abd-El Rahman Ahmed, Nasser Ghanem, Sherif Mohamed Dessouki, Marwa Said Faheem, Ahmed Yehia Gad \\ and Ashraf Hesham Barkawi*
}

Department of Animal Production, Faculty of Agriculture, Cairo University, Giza, Egypt.

*Corresponding author's Email: ashrafb53@yahoo.com; DorciD: 0000-0002-9979-1003

\begin{abstract}
The aim of this investigation was to follow up in vitro preimplantation development of buffalo cumulus-oocyte complexes (COCs) after BCB test and followed by in vitro maturation under two different levels of oxygen tension. Cumulus-oocyte complexes $(n=1045)$ were selected with $B C B$ staining (oocytes with any degree of blue color in cytoplasm was defined as $\mathrm{BCB}+$, oocytes without any degree of blue color in cytoplasm was defined as $\mathrm{BCB}-$ ) in addition to a third control group. The previous experimental groups $(\mathrm{BCB}+, \mathrm{BCB}-$, control) were matured in vitro under low (5\%) and high oxygen tension (20\%), followed by in vitro fertilization and in vitro culture of presumptive zygotes. There were no differences $(\mathrm{P} \leq 0.05)$ in cleavage, morula and transferable embryos rates among $\mathrm{BCB}+$, $\mathrm{BCB}-$ and control group. However, blastocyst rate was greater significantly in control group (14.4 \pm 2.0$)$ than $\mathrm{BCB}$ COCs $(8.4 \pm 1.9)$. According to the oxygen tension effect, the rate of morula and transferable embryos was increased $(\mathrm{P} \leq 0.05)$ in buffalo COCs developed under low oxygen tension $(11.6 \pm 1.4$ and $23.8 \pm 1.9)$ compared to high oxygen tension group $(7.4 \pm 1.4$ and $17.9 \pm 2.1)$. In addition, cleavage, morula, blastocyst and transferable embryos rates were greater in $\mathrm{BCB}+$ under low $(43.6 \pm 3.9,14.9 \pm 2.5,14.1 \pm 2.9$ and $28.4 \pm 3.6)$ than high oxygen tension group $(33.5 \pm 3.9,7.1 \pm 2.5,11.6 \pm 2.9$ and $18.8 \pm 3.6)$ which may reflect enhanced biological processes controlling early development. Moreover, blastocyst rate was significantly higher in control group cultured under high (12.0 \pm $2.9)$ and low $(16.9 \pm 2.8)$ oxygen level than their counterparts of BCB- group $(9.3 \pm 2.9$ and $7.6 \pm 2.6$, respectively). In conclusion, there was no differences in embryo development between $\mathrm{BCB}+$ and $\mathrm{BCB}-, \mathrm{COCs}$; therefore, oocyte selection based on BCB staining is not an effective tool to select developmental competent buffalo COCs. Buffalo morula and transferable embryos prefer low oxygen tension for early development, which should be applied during in vitro embryo production of this species.
\end{abstract}

Keywords: Brilliant cresyl-blue staining, Cumulus-oocyte complex, Morula, Preimplantation.

\section{INTRODUCTION}

Egyptian buffaloes represent an important livestock resource for producing meat and milk production in agriculture national economy. Reproductive efficiency is a key factor affecting female buffalo productivity; however, buffaloes are characterized by late of puberty and sexual maturity, long postpartum, poor oestrous signs, low pregnancy rate and long calving intervals (Barile, 2005). Noteworthy, several Assisted Reproductive Technologies (ART's) are becoming important tools that applied for accelerating the genetic gain of milk production and enhancing efficacy of dairy animal's reproductive performance (Hafez, 2015).

In this regard, in vitro production of buffalo embryos (IVEP) technique has improved during the last decades. However, the quality and rate of transferable embryos produced still low than that required for breeding programs (Gasparrini, 2007; Goszczynsk et al., 2018). It is well established that the development of embryos depends on various factors like culture conditions (in vivo versus in vitro conditions), constituents of culture media, $\mathrm{pH}$ and oxygen tension (Simopoulou et al., 2018).

Suboptimal conditions for in vitro culture eventually reduced the development rate and quality of blastocysts because of reactive oxygen species (ROS) accumulated during pre-implantation development due to insufficient oxygen level (Bavister, 1995; Karagenc et al., 2004; Oyamada and Fukui, 2004; Torres-Osorio et al., 2019). The primary gas phases used in IVF laboratories are 5\% carbon dioxide $\left(\mathrm{CO}_{2}\right)$ in air $\left(20 \% \mathrm{O}_{2}\right)$, and $90 \%$ Nitrogen $\left(\mathrm{N}_{2}\right)$. The oxygen level of most mammalian species in the oviduct and uterus ranged from 2 to $8 \%$ (Fischer et al., 1992). There is a balanced system in any living cell, which keeps the oxygen species generation and scavenging in balance (He et al., 2017). An imbalance between the Reactive Oxygen Species (ROS) produced and the intracellular antioxidants causes oxidative stress (Fiers et al., 1999).

Various types of ROS cause oxidative stress, which either produced intracellularly or derived from extracellular environment. Indeed, the main sources of ROS are free radicals such as superoxide anion, hydrogen peroxide, hydroxyl 
radical, hydroxyl ion, and nitric oxide produced during oxygen reduction reactions (Balaban et al., 2005; Agarwal et al., 2006). The effects of ROS in mammalian reproductive tract could be negative or positive depends on the duration of exposure and level of ROS (Agarwal et al., 2005). Indeed, an adequate amount of ROS is required for ovarian steroid biosynthesis and induction of ovulation events.

Physiological levels of ROS are required during in vitro maturation (IVM) to reinitiate meiosis of the oocytes (Shkolnik et al., 2011). However, an elevated level of ROS during in vitro maturation can cause chromosomal errors and finally reduced developmental competence of the oocyte (Sasaki et al., 2019). Increased ROS generation has been shown to cause alterations in the organization of microtubules and chromosomal alignment of metaphase II meiotic spindles in mouse oocytes (Cheung et al., 2016; Kala et al., 2016). Moreover, minimal levels of oxidative stress during embryonic growth may be beneficial for early development (Combelles et al., 2009; Shkolnik et al., 2011). In contrast, embryos exposed to high levels of ROS are morphologically poor quality and at risk of early embryonic development blockage. An increase in ROS production has been found to result in embryonic arrest at two-cell stage of development (Du plessis et al., 2008; Ashraf et al., 2016). Therefore, the current study was designed to assess the developmental competence of buffalo oocyte after in vitro maturation under two levels of oxygen tension followed by in vitro fertilization and early embryonic development up to the blastocyst stage.

\section{MATERIALS AND METHODS}

\section{Experimental design}

Good quality COCs of grade A and B were used in the current investigation. In this experiment, good quality cumulus-oocyte complexes (COCs) were distributed in three groups (BCB+,BCB- and control) and according to oxygen tension divided into two subgroups as follows: Control 5\% $\mathrm{n}=160$, Control $20 \% \mathrm{n}=174, \mathrm{BCB}+5 \% \mathrm{n}=160, \mathrm{BCB}+20 \%$ $\mathrm{n}=197$, and BCB-5\% $\mathrm{n}=169, \mathrm{BCB}-20 \% \mathrm{n}=185)$.

\section{Collection of ovaries and oocyte retrieval}

Buffalo ovaries $(n=1045)$ were collected from local slaughterhouses (El-Monieb and El-Warak) during Winter season, from October 2019 to March 2020. Within 3 hrs after slaughtering, ovaries were transported to the laboratory (Embryology Lab, Research Park, Faculty of Agriculture, Cairo University) in physiological saline $(0.9 \% \mathrm{NaC} 1$ supplemented with $50 \mu \mathrm{g} / \mathrm{ml}$ gentamycin) and maintained at $34-37^{\circ} \mathrm{C}$. Ovaries were washed once in $70 \%$ ethanol and three times in warm sterile physiological saline. Cumulus-oocyte complexes (COCs) were collected by aspiration of antral follicles using 18-gauge needle attached to a 10-ml syringe. Oocytes were washed twice in washing medium TCM-199-Hepes medium supplemented with $2 \%$ fetal bovine serum (FBS), $0.3 \mathrm{mg} / \mathrm{ml}$ glutamine and $50 \mu \mathrm{g} / \mathrm{ml}$ gentamycin. The evaluation of recovered COCs was done under a stereo microscope, according to their cumulus layers and ooplasm homogeneity as stated by (Chauhan et al., 1998). Compact COCs that had a mass of $\geq 5$ layers of cumulus cells and homogeneous ooplasm (Grade-A) and those had 3-4 layers of cumulus cells and homogeneous ooplasm (Grade-B) were used in the current study.

\section{Brilliant cresyl blue staining test}

Cumulus-oocyte complexes were washed three times in Dulbecco's PBS (DPBS) and adjusted by adding $0.4 \%$ BSA (Fraction V), then COCs were exposed to $26 \mathrm{mM}$ of BCB (B-5388, Sigma) and diluted in mDPBS at $38.5^{\circ} \mathrm{C}$ for $90 \mathrm{~min}$ in a humidified air atmosphere without $\mathrm{CO}_{2}$. Directly after washing twice in mDPBS, COCs were examined under a stereomicroscope and according to their cytoplasm coloration were divided into two classes (Figure 1); oocytes with any degree of blue cytoplasm coloration $(\mathrm{BCB}+)$ and oocytes with no blue cytoplasm coloration (BCB-), While control group was incubated immediately without BCB exposure.

Figure 1. Brilliant cresyl blue stained of Egyptian buffalo oocytes. Blue stained oocytes are designated as brilliant cresyl blue $(\mathrm{BCB}+)$ and colorless oocytes are designated as brilliant cresyl blue (BCB-).

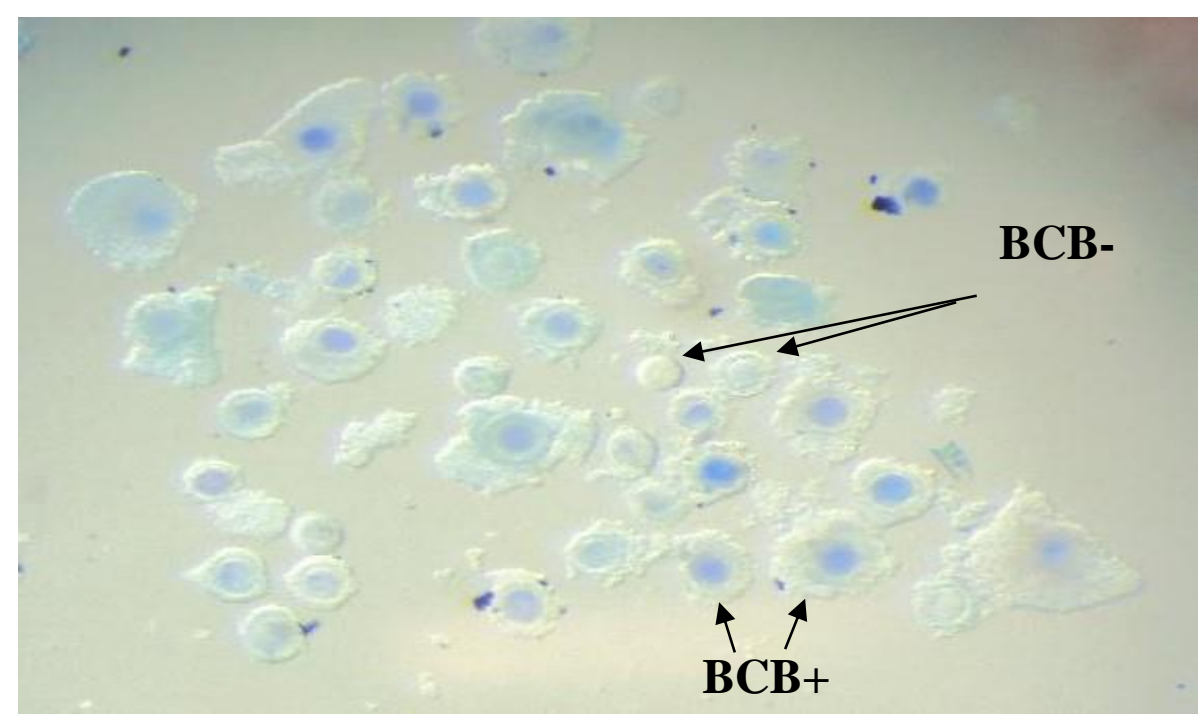




\section{In vitro oocytes maturation}

Before commencing the maturation process, the maturation medium was prepared in advance. The medium was held for equilibrium at $38.5^{\circ} \mathrm{C}$ and $5 \% \mathrm{CO}_{2}$ and incubated for $2 \mathrm{hrs}$. All COC groups were washed twice in the ripening medium consisting of TCM-199 combined with $10 \%$ FBS (F7524, Sigma, Germany), $1 \mu \mathrm{g} / \mathrm{ml}$ estradiol-17 $\beta$ (E2758, Sigma, USA), $0.15 \mathrm{mg} / \mathrm{ml}$ glutamine, $22 \mu \mathrm{g} / \mathrm{ml}$, Na-pyruvate (P-4562;Sigma, USA), $5 \mu \mathrm{g} / \mathrm{ml}$ FSH (F2293, Sigma, USA), and $50 \mu \mathrm{g} / \mathrm{ml}$ gentamycin. A total of 10-15 COCs were seeded from each category (Control, BCB+, BCB-) in drops of $100 \mu \mathrm{l}$ of maturation medium under mineral oil (M8410, Sigma, USA) in a $3.5 \mathrm{~cm}$ Petri dish. The cumulusoocyte complexes were incubated at $38.5^{\circ} \mathrm{C}$ for $24 \mathrm{hrs}$ in a humidified atmosphere with $5 \% \mathrm{CO}_{2}$ under $5 \%$ oxygen level or $20 \%$ oxygen level.

\section{In vitro fertilization}

Frozen straw of Egyptian buffalo bull semen $(0.25 \mathrm{ml})$ was thawed in warmed water at $38^{\circ} \mathrm{C}$ for 30 seconds and opened after wiped with $70 \%$ ethanol alcohol. Spermatozoa were washed twice in the sperm washing medium namely Tyrode Albumin Lactate Pyruvate (TALP) medium (modified Ca2+ free TALP medium) by centrifugation at $1800 \mathrm{rpm}$ for $5 \mathrm{~min}$ and one time in fertilization medium (modified TALP medium) according to Stinshoff et al. (2011). Spermatozoa pellet was re-suspended in the fertilization medium. The concentration of sperm was adjusted to be $2 \times 106$ (Gasparrini, 2002). Matured oocytes (10-15 oocytes per drop) were placed in a small petri dish containing $50 \mu 1$ droplets of fertilization medium. Aliquots of the sperm suspension were added to each droplet containing mature oocytes. The oocytes and sperm were co-cultured in an incubator at $38.5^{\circ} \mathrm{C}$ in $5 \% \mathrm{CO}_{2}$ in air, with maximal humidity for 18 hrs.

\section{In vitro culture}

The received zygotes were washed four times after $18 \mathrm{hrs}$ of fertilization by repeated pipetting to denude cumulus cells. The presumptive zygotes of all groups (control, BCB+ and BCB-) were placed into $50 \mu 1$ droplets of in vitro culture medium in 4 well petri dish and covered with paraffin oil. The culture medium composed of TCM-199 supplemented with $3 \mathrm{mg} / \mathrm{ml} \mathrm{BSA,} 22 \mu \mathrm{g} / \mathrm{ml} \mathrm{Na-pyruvate,} 10 \mu \mathrm{l} / \mathrm{ml} \mathrm{NEAA} \mathrm{(100} \mathrm{X),} 20 \mu \mathrm{l} / \mathrm{ml}$ EAA (50 X) and $50 \mu \mathrm{g} / \mathrm{ml}$ gentamycin sulphate. During the culture period, presumptive zygotes were kept at $38.5^{\circ} \mathrm{C}$ in a humidified atmosphere of $5 \% \mathrm{CO}_{2}$ in air. Half of the medium was changed every $48 \mathrm{hrs}$, the cleavage rate was checked after 48 hrs post insemination (Figure 2) and blastocyst rate was checked on day 7 (Figure 3).

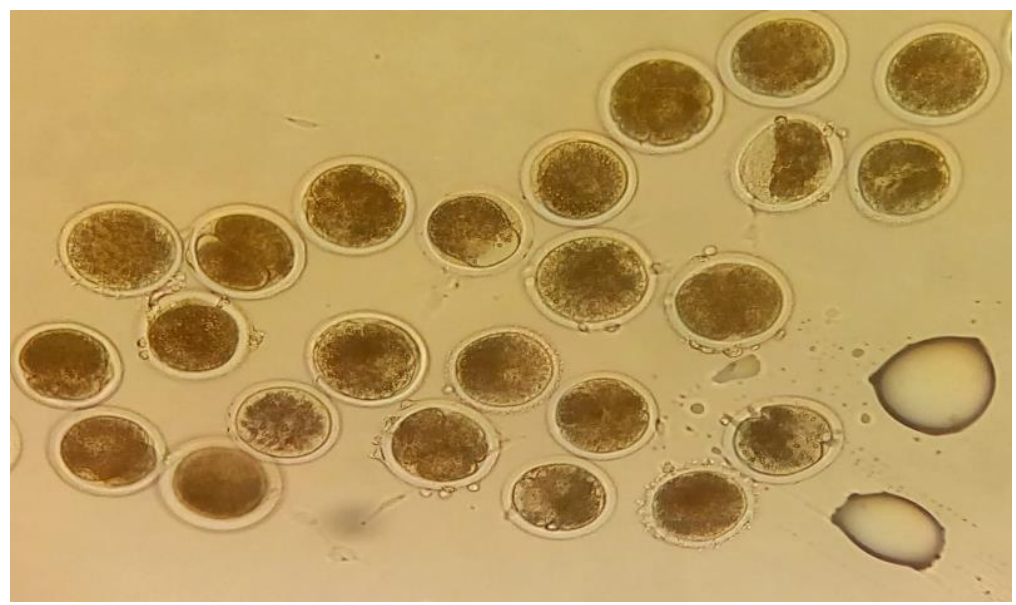

Figure 2. Embryos at 2-Cell, 4-Cell, 8-Cell and degenerated embryos after 48 hours of culture under oxidative stress $\left(20 \% \mathrm{O}_{2}\right)$ in Egyptian buffalo oocytes

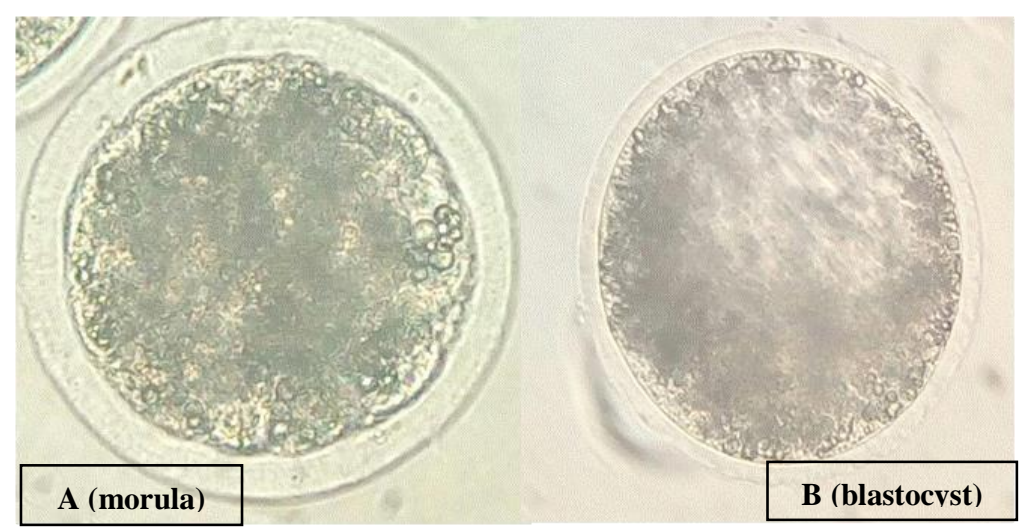

Figure 3. Embryos at morula and blastocyst stages under $5 \% \mathrm{O}_{2}$ level in Egyptian buffalo oocytes 


\section{Statistical analysis}

Statistical analysis of current data was done using the SPSS program package (SPSS Inc., Chicago, 183 Illinois, USA). The effect of oxygen level (5\% versus $20 \%$ ) and oocyte type (BCB+ versus BCB- versus control) on the previous traits were tested by applying the following model:

Yijk1 $=\mu+R i+A j+(R i * A j) i j k+e i j k 1$

Where:

$\mathrm{Y}$ ijk1 $=$ individual observation; $\mu=$ Overall mean; $\mathrm{Ri}=$ Effect of $\mathrm{BCB}$ staining $(\mathrm{BCB}+=1$ and $\mathrm{BCB}-=2) ; \mathrm{Aj}=\mathrm{Effect}$ of oxygen level $(5 \%=1$ and $20 \%=2) ;\left(\mathrm{Ri}^{*} \mathrm{Aj}\right) \mathrm{ijk}=$ The interaction between $\mathrm{BCB}$ and oxygen level; e $\mathrm{ijk} 1=$ Experimental error supposed to be randomly distributed $(0, \sigma 2)$. The data were expressed as mean \pm standard error. Probability values up to $\leq 5 \%$ was considered significant.

\section{Ethical approval}

The present work has been conducted in accordance with the guidelines of the ethical committee of Faculty of Agriculture, Cairo University. The experimental lab work was executed at Cairo University Research Park, Faculty of Agriculture, Cairo University, Egypt.

\section{RESULTS AND DISCUSSION}

Although the efficiency of In vitro embryo production has improved in Buffalo, the rate of transferable embryos (TE) and the rate of development to term is still very low (Gasparrini, 2002). The outcome and quality of in vitro produced embryos are generally still lower than in vivo counterparts in other mammalian species (Marsico et al., 2019). Different factors play a key role in assessing the quality of in vitro production (IVP). The competence of COCs to reach transferable embryos stages is considered one of the main factors influencing the yield of the pre-implantation embryos (Reader et al., 2017), while the conditions of culture affect the quality of the blastocysts (Rizos et al., 2002). In the current study, we investigated the interaction of oxygen tension levels with the quality of buffalo oocytes (using BCB staining model) after in vitro maturation, fertilization and early embryonic development up to the blastocyst stage.

\section{Embryonic development of buffalo oocytes under two levels of oxygen tension}

The results indicated that there were no significant differences between experimental groups (BCB+, BCB-, and control) neither in cleavage rate nor in the rates of morula and transferable embryos developed under the two oxygen levels. However, the cleavage, morula, blastocyst and transferable embryos rates were greater in BCB+ under low than high oxygen level (Table 1). Moreover, blastocyst rate was significantly increased in the control group compared to BCB- oocyte group when cultured under low and high oxygen tension (Table 1 and figure 4). The improvement of development rates of preimplantation embryos of $\mathrm{BCB}+$ group under low compared to high oxygen tension may reflect enhanced biological processes controlling early development. Indeed, embryo development rate was enhanced when the intracellular mitochondrial activity was increased under low level of oxygen (Ma et al., 2017; Belli et al., 2019). Noteworthy, High oxygen tension could cause oxidative stress which directly compromises early embryonic development by disturbing mitochondria (Ma et al., 2017).

The increased blastocyst rate of control group compared to BCB- is due to lower total number of embryo cells and mitochondria content of BCB- group (Fakruzzaman et al., 2013). Selection of COCs based on BCB staining during IVP of bovine indicated improvement of blastocyst development rate, quality, activity of mitochondria and increased expression of pregnancy associated candidate genes in BCB+ compared to BCB- group (Fakruzzaman et al., 2013). This indicates that the increased development rate of $\mathrm{BCB}+$ embryos under low oxygen tension is due to its inherent intracellular potential.

Table 1. Cleavage rate, morula rate, blastocyst rate and transferable embryos rate of buffalo COCs either selected with BCB staining or cultured under low and high oxygen tension

\begin{tabular}{lcccc|cccc}
\hline \multirow{2}{*}{ Groups } & \multicolumn{3}{c|}{ Oxygen level (5\%) } & \multicolumn{3}{c}{ Oxygen level (20\%) } \\
\cline { 2 - 8 } & $\begin{array}{c}\text { Cleavage* } \\
\text { rate (\%) }\end{array}$ & $\begin{array}{c}\text { Morula rate } \\
(\%)\end{array}$ & $\begin{array}{c}\text { Blastocyst } \\
\text { rate (\%) }\end{array}$ & $\begin{array}{c}\text { Transferable } \\
\text { embryos ** } \\
(\boldsymbol{\%})\end{array}$ & $\begin{array}{c}\text { Cleavage* } \\
\text { rate (\%) }\end{array}$ & $\begin{array}{c}\text { Morula } \\
\text { rate (\%) }\end{array}$ & $\begin{array}{c}\text { Blastocyst } \\
\text { rate (\%) }\end{array}$ & $\begin{array}{c}\text { Transferable } \\
\text { embryos ** } \\
(\%)\end{array}$ \\
\hline Control & $35.5 \pm 3.7^{\mathrm{a}^{* * *}}$ & $7.7 \pm 2.3^{\mathrm{a}}$ & $16.9 \pm 2.8^{\mathrm{a}}$ & $24.3 \pm 3.4^{\mathrm{a}}$ & $31.6 \pm 3.9^{\mathrm{a}}$ & $6.1 \pm 2.5^{\mathrm{a}}$ & $12.0 \pm 2.9^{\mathrm{a}}$ & $17.9 \pm 3.6^{\mathrm{a}}$ \\
BCB+ & $43.6 \pm 3.9^{\mathrm{a}}$ & $14.9 \pm 2.5^{\mathrm{a}}$ & $14.1 \pm 2.9^{\mathrm{ab}}$ & $28.4 \pm 3.6^{\mathrm{a}}$ & $33.5 \pm 3.9^{\mathrm{a}}$ & $7.1 \pm 2.5^{\mathrm{a}}$ & $11.6 \pm 2.9^{\mathrm{ab}}$ & $18.8 \pm 3.6^{\mathrm{a}}$ \\
BCB- & $30.3 \pm 3.6^{\mathrm{a}}$ & $12.1 \pm 2.2^{\mathrm{a}}$ & $7.6 \pm 2.6^{\mathrm{b}}$ & $18.9 \pm 3.2^{\mathrm{a}}$ & $34.5 \pm 3.9^{\mathrm{a}}$ & $9.0 \pm 2.5^{\mathrm{a}}$ & $9.3 \pm 2.9^{\mathrm{b}}$ & $17.1 \pm 3.6^{\mathrm{a}}$ \\
\hline
\end{tabular}

Values with different superscripts across treatments within the same column indicate significant differences $(\mathrm{P} \leq 0.05)$. ${ }^{*}$ Cleavage rate $=$ Numbers of oocytes cleaved/Numbers of oocytes inseminated; **Transferable embryos (Day 7): numbers of morula and blastocyst embryos; ${ }^{* * *}$ Least Square Means \pm Standard Error; BCB+: oocytes with any degree of blue color in cytoplasm; BCB-: oocytes without any degree of blue color in cytoplasm 


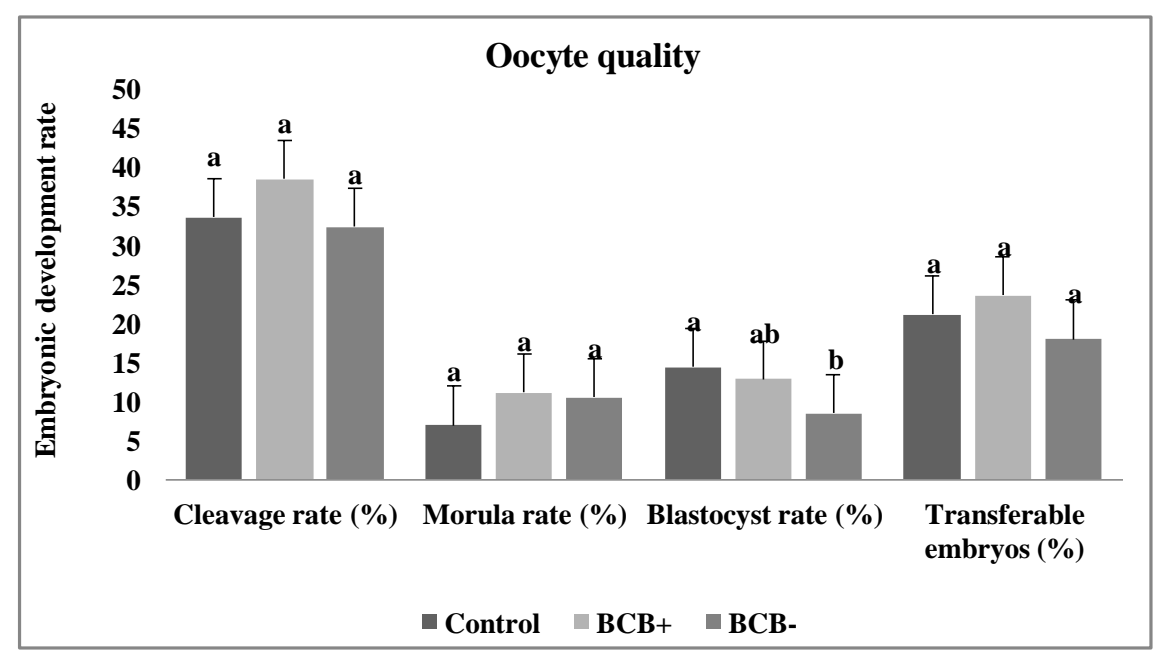

Figure 4. Effect of oocytes brilliant cresyl blue staining on in vitro embryonic development of Egyptian buffalo oocytes. Bars with different superscripts $(a, b)$ indicate significant differences $(\mathrm{P} \leq 0.05)$.

\section{Effect of brilliant cresyl blue staining}

The inefficiency of in vitro embryo production was associated with oocyte quality at the beginning of maturation (Gasparrini, 2002). Identifying and selecting oocytes with high developmental competence is a critical step towards successful embryo technology (Egerszegi et al., 2010). Many studies used brilliant cresyl blue (BCB) staining tests to monitor and identify oocyte quality for different species such as buffalo and ovine (Manjunatha et al., 2007; Wang et al., 2012).

Previous work has shown that $\mathrm{BCB}+$ oocytes are more competent and yield more blastocysts compared to $\mathrm{BCB}-$ oocytes. $\mathrm{BCB}$ testing has been shown to enable the selection of larger oocytes with higher levels of in vitro maturation and fertilization and an increased percentage of normal fertilized oocytes (Wang et al., 2012). The ability of BCB+ derived oocyte to be fertilized and developed to morula and blastocyst stages was significantly higher than morphologically selected oocytes only (Rodriguez-Gonzalez et al., 2003; Alm et al., 2005; Manjunatha et al., 2007; Silva et al., 2013). Indeed, BCB selects larger oocytes with more mitochondria and activation of the maturation-promoting factor (MPF) (Catalá et al., 2011). On the other side, less competent oocytes (BCB-) displayed fertilization failure or developmental arrest due to delayed mitochondrial DNA (mtDNA) replication attributed to the delayed expression of their nuclear replication factors.

Our results indicated a lower blastocyst rate in BCB- oocytes than control group (Table 2 and figure 4). In agreement with our findings, Wongsrikeao et al. (2006) reported that BCB staining has a negative impact on the cleavage and development of porcine embryos after in vitro maturation. Opiela et al. (2008) consider the BCB staining test as questionable because of the lack of significant differences in blastocyst formation between $\mathrm{BCB}+$ and control group. Pawlak et al. (2014) stated that BCB staining test was less successful selection method with high apoptosis incidence and major variations in the diameter of the BCB+ oocyte. In contrast, Manjunatha et al. (2007) stated that before in vitro maturation, staining of buffalo oocytes with BCB stain had identified developmentally competent oocytes for IVP. Relative to conventional oocyte selection based solely on morphology, the yield of blastocyst has been significantly improved in BCB+ selected oocytes. Fathi et al. (2017) found that in BCB+ groups, indices of early embryonic development; cleavage, morula and blastocyst stage growth were substantially improved compared to the $\mathrm{BCB}-$ and control groups.

Table 2. Effect of oocytes quality on in vitro embryonic development of Egyptian buffalo oocytes

\begin{tabular}{lcccc}
\hline Treatments & $\begin{array}{c}\text { Cleavage rate } \\
(\boldsymbol{\%})\end{array}$ & $\begin{array}{c}\text { Morula rate } \\
(\boldsymbol{\%})\end{array}$ & $\begin{array}{c}\text { Blastocyst rate } \\
(\boldsymbol{\%})\end{array}$ & $\begin{array}{c}\text { Transferable embryos** } \\
(\boldsymbol{\%})\end{array}$ \\
\hline Control & $33.6 \pm 2.7^{\mathrm{a}^{* * *}}$ & $6.9 \pm 1.7^{\mathrm{a}}$ & $14.4 \pm 2.0^{\mathrm{a}}$ & $21.1 \pm 2.5^{\mathrm{a}}$ \\
BCB+ & $38.5 \pm 2.8^{\mathrm{a}}$ & $11.1 \pm 1.8^{\mathrm{a}}$ & $12.8 \pm 2.1^{\mathrm{ab}}$ & $23.6 \pm 2.5^{\mathrm{a}}$ \\
BCB- & $32.4 \pm 2.7^{\mathrm{a}}$ & $10.5 \pm 1.7^{\mathrm{a}}$ & $8.4 \pm 1.9^{\mathrm{b}}$ & $18.0 \pm 2.4^{\mathrm{a}}$ \\
\hline
\end{tabular}

Values with different superscripts $(\mathrm{a}, \mathrm{b})$ across treatments within one column indicate significant differences $(\mathrm{P} \leq 0.05)$. ${ }^{*}$ Cleavage rate $=$ Numbers of oocytes cleaved/Numbers of oocytes inseminated; **Transferable embryos (Day 7): numbers of morula and blastocyst embryos; ${ }^{* * *}$ Least Square Means \pm Standard Error; BCB+: oocytes with any degree of blue color in cytoplasm; BCB-: oocytes without any degree of blue color in cytoplasm

\section{Oxygen concentration}

Karagenc et al. (2004) found that high oxygen concentrations (20\% in air) decreased the percentage of embryonic development due to increased level of ROS in rodents, swine (Kitagawa et al., 2004; Booth et al., 2005), goats (Batt et al., 1991) and bovine (Takahashi et al., 2000). According to the oxygen tension effect, the rate of morula and transferable 
embryos was increased $(\mathrm{P} \leq 0.05)$ in buffalo COCs developed under low oxygen tension compared to high oxygen tension group (Table 3 and figure 5).

Table 3. Effect of oxygen levels on in vitro embryonic development in Egyptian buffalo oocytes

\begin{tabular}{lcccc}
\hline Oxygen level & $\begin{array}{c}\text { Cleavage rate } \\
(\boldsymbol{\%})\end{array}$ & $\begin{array}{c}\text { Morula rate } \\
(\boldsymbol{\%})\end{array}$ & $\begin{array}{c}\text { Blastocyst rate } \\
(\boldsymbol{\%})\end{array}$ & $\begin{array}{c}\text { Transferable embryos** } \\
(\boldsymbol{\%})\end{array}$ \\
\hline $\mathbf{5 \%}$ & $36.5 \pm 2.2^{\mathrm{a}^{* * *}}$ & $11.6 \pm 1.4^{\mathrm{a}}$ & $12.8 \pm 1.6^{\mathrm{a}}$ & $23.8 \pm 1.9^{\mathrm{a}}$ \\
$\mathbf{2 0 \%}$ & $33.2 \pm 2.3^{\mathrm{a}}$ & $7.4 \pm 1.4^{\mathrm{b}}$ & $10.9 \pm 1.7^{\mathrm{a}}$ & $17.9 \pm 2.1^{\mathrm{b}}$ \\
\hline
\end{tabular}

Values with different superscripts $(\mathrm{a}, \mathrm{b})$ across treatments within one column indicate significant differences $(\mathrm{P} \leq 0.05)$. ${ }^{*}$ Cleavage rate $=$ Numbers of oocytes cleaved/Numbers of oocytes inseminated; **Transferable embryos (Day 7): numbers of morula and blastocyst embryos; ${ }^{* * *}$ Least Square Means \pm Standard Error; BCB+: oocytes with any degree of blue color in cytoplasm; BCB-: oocytes without any degree of blue color in cytoplasm

However, there were no significant differences in cleavage and blastocyst rates under two oxygen levels. In terms of blastocyst formation, embryo developmental competence was significantly higher in embryos grown under low concentration of oxygen $\left(5 \% \mathrm{O}_{2}+5 \% \mathrm{CO}_{2}+90 \% \mathrm{~N}_{2}\right)$ than those developed in atmospheric oxygen $\left(\right.$ air $\left.+5 \% \mathrm{CO}_{2}\right)$ in bovine (Thompson et al., 1990; Liu and Foote, 1995), mouse (Orsi and Leese, 2001) human (Dumoulin et al., 1999) and porcine (Booth et al., 2005). Similarly, for the development of high-quality ovine blastocysts, high oxygen concentration (20 versus $5 \% \mathrm{O}_{2}$ ) during IVF was found to be unfavorable (Leoni et al., 2007). Amin et al. (2014) found that there was no significant difference in the cleavage rate between groups. On the other hand, cultivating embryos below $5 \%$ oxygen resulted in blastocyst levels significantly higher $(\mathrm{P} \leq 0.05)$ than those cultivated at $20 \%$ oxygen.

The high concentration of $\mathrm{O}_{2}$ in the culture media can increase certain enzymatic reactions, such as xanthine oxidase and NADPH oxidase activity, leading to increased levels of ROS in embryonic cells (Goto et al., 1993; Lopes et al., 2010). The high level of intracellular ROS increased incidence of DNA damage, lipid peroxidation, and apoptosis, which subsequently reduced embryo development (Takahashi, 2012). The physiological level of oxygen has enhanced embryo development through regulation of development related genes (Rinaudo et al., 2006; Bermejo-Álvarez et al., 2010).

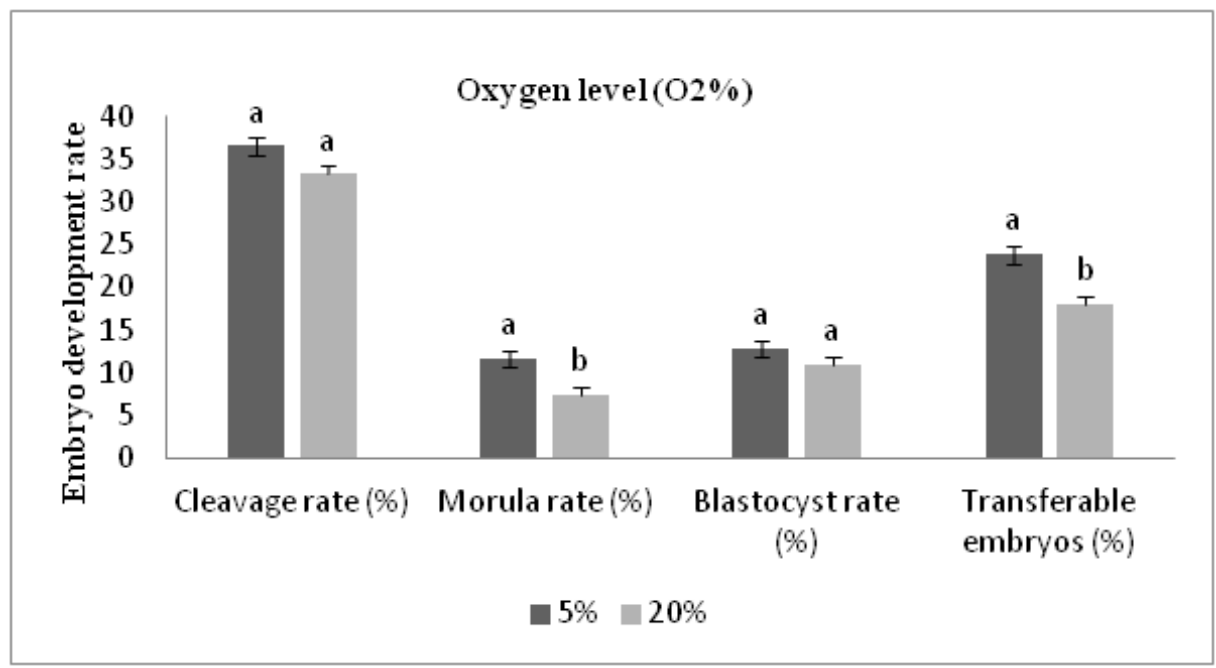

Figure 5. In vitro embryonic development of Egyptian buffalo oocytes under two oxygen levels. Bars with different superscripts $(a, b)$ indicate significant differences $(\mathrm{P} \leq 0.05)$.

\section{CONCLUSION}

The results of the present investigation have clearly indicated that preimplantation embryo development is similar in $\mathrm{BCB}+$ and $\mathrm{BCB}-\mathrm{COCs}$, which discourages the use of this test in the selection of buffalo COCs. Moreover, transferable buffalo embryos (morula and blastocyst) developed at a higher rate under low oxygen tension $\left(5 \% \mathrm{O}_{2}\right)$. Therefore, it is recommended to culture buffalo pre-implantation embryos at $5 \%$ of oxygen during in vitro development.

\section{DECLARATIONS}

\section{Competing interests}

The authors have no competing interests, and we are with respect to this search and in agreement with each other. In addition, we have no conflict with authorship or article publication. 


\section{Author`s contribution}

All authors have contributed to design of the study, writing and revision of the manuscript. In addition, Dalia Abdel Rahman Ahmed who conducted the laboratory work, analyzed the data wrote the research article. All the authors approved and agreed to publish the manuscript.

\section{REFERENCES}

Agarwal A, Gupta S and Sharma RK (2005). Role of oxidative stress in female reproduction. Reproductive Biology and Endocrinology, 3: 28-47. DOI: https://dx.doi.org/10.1186\%2F1477-7827-3-28

Agarwal A, Said TM, Bedaiwy MA, Banerjee J and Alvarez JG (2006). Oxidative stress in an assisted reproductive technique setting. Fertility and Sterility, 86: 503-512. DOI: https://doi.org/10.1016/j.fertnstert.2006.02.088

Alm H, Torner H, Loehrke B, Viergutz T, Ghoneim IM and Kanitz W (2005). Bovine blastocyst development rate in vitro is influenced by selection of oocytes by brilliant cresyl blue staining before IVM as indicator for glucose-6-phosphate dehydrogenase activity. Theriogenology, 63: 21942205. DOI: https://doi.org/10.1016/j.theriogenology.2004.09.050

Amin, A, Gad A, Salilew-Wondim D, Presto would S, Held E, Hoelker M, Rings F, Then E, Neuhoff C, Loft C, Scheuander K and Tuesday D (2014). Bovine embryo survival under oxidative-stress conditions is associated with activity of the NRF2-mediated oxidative-stress-response pathway. Molecular Reproduction and Development, 81: 497-513. DOI: https://doi.org/10.1002/mrd.22316

Ashraf S, Raies -Ul-Haq M, Dhanda S, Kumar A, Goud ST, Chauhan MS and Upadhyay RC (2016). Heat stress and antioxidant enzyme activity in bubaline (Bubalus bubalis) oocytes during in vitro maturation. International Journal of Biometeorology, 60(9): 1-10. DOI: https://doi.org/10.1007/s00484-015-1129-0.

Balaban RS, Nemoto S and Finkel T (2005). Mitochondria, oxidants, and aging. Cell, 120: 483-495. DOI: https://doi.org/10.1016/j.cell.2005.02.001

Barile VL (2005). Improving reproductive efficiency in female buffaloes. Livestock Production Science, 92: 183-194. DOI: https://doi.org/10.1016/j.livprodsci.2004.06.014Get rights and content

Batt P, Gardner D and Cameron A (1991). Oxygen concentration and protein source affect the development of preimplantation goat embryos in vitro. Reproduction Fertility and Development, 3(5): 601. DOI: https://doi.org/10.1071/rd9910601

Bavister BD (1995). Culture of preimplantation embryos: facts and artifacts. Human Reproduction Update, 1: 91-148. DOI: https://doi.org/10.1093/humupd/1.2.91

Belli M, Zhang L, Liu X, Donjacour A, Ruggeri E, Palmerini MG, Nottola SA, Macchiarelli G and Rinaudo P (2019). Oxygen concentration alters mitochondrial structure and function in in vitro fertilized preimplantation mouse embryos. Human Reproduction, 34(4): 601-611. DOI: https://doi.org/10.1093/humrep/dez011.

Bermejo-Álvarez, P, Lonergan P, Rizos D and Gutiérrez-Adan A (2010). Low oxygen tension during IVM improves bovine oocyte competence and enhances anaerobic glycolysis. Reproductive Biomedicine Online, 20(3): 341-349. DOI: https://doi.org/10.1016/j.rbmo.2009.12.006

Booth b PJ, Holm P and Callesen H (2005). The effect of oxygen tension on porcine embryonic development is dependent on embryo type. Theriogenology, 63(7): 2040-2052. DOI: https://doi.org/10.1016/j.theriogenology.2004.10.001

Catalá MG, Izquierdo D, Uzbekova S, Morató R, Roura M, Romaguera R, Papillier P and Paramio MT (2011). Brilliant Cresyl Blue stain selects largest oocytes with highest mitochondrial activity, maturation-promoting factor activity and embryo developmental competence in prepubertal sheep. Reproduction, 142(4): 517-527. DOI: https://doi.org/10.1530/REP-10-0528

Chauhan MS, Singla SK, Palta P, Manik RS and Madan ML (1998). In vitro maturation and fertilization, and subsequent development of buffalo (Bubalus Bubalis) embryos: effects of oocytes quality and type of serum. Reproduction Fertility and Development, 10: 173-1 77. DOI: $\underline{10.1071 / \mathrm{r} 97080}$

Cheung EC, Lee P, Ceteci F, Nixon C, Blyth K, Sansom OJ and Vousden KH (2016). Opposing effects of TIGAR- and RAC1-derived ROS on Wntdriven proliferation in the mouse intestine. Genes Development, 30: 52-63. DOI: https://doi.org/10.1101/gad.271130.115

Combelles CM, Gupta S and Agarwal A (2009). Could oxidative stress influence the in-vitro maturation of oocytes?. Reproductive Biomedecine Online, 18(6): 864-680. DOI: https://doi.org/10.1530/REP-10-0528

Du Plessis SS, Makker K, Desia NR and Agrawal A (2008). Impact of oxidative stress on IVF. Expert Reviews Obstetrics and Gynecology, 3(4):539554. DOI: https://doi.org/10.1586/17474108.3.4.539

Dumoulin JCM, Meijers CJJ, Bras M, Coonen E, Geraedts JPM and Evers JLH (1999). Effect of oxygen concentration on human in vitro fertilization and embryo culture. Human Reproduction, 14: 465-469. DOI: https://doi.org/10.1093/humrep/14.2.465

Egerszegi I, Alm H, Rátky J, Heleil B, Brüssow KP and Torner H (2010). Meiotic progression, mitochondrial features and fertilization characteristics of porcine oocytes with different G6PDH activities. Reproduction Fertility and Development, 22: 830-838. DOI: https://doi.org/10.1071/RD09140

Fathi M, Ashry M, Salama A and Badr MR (2017). Developmental competence of Dromedary camel (Camelus dromedarius) oocytes selected using brilliant cresyl blue staining. Zygote, 25(4): 529-536. DOI: https://doi.org/10.1017/S0967199417000387

Fakruzzaman M, Bang JI, Lee KL, Kim SS, Ha AN, Ghanem N, Han CH, Cho KW, White KL and Kong IK (2013). Mitochondrial content and gene expression profiles in oocyte-derived embryos of cattle selected on the basis of brilliant cresyl blue staining. Animal Reproductive Science, 142(1-2):19-27. DOI: https://doi.org/10.1016/j.anireprosci.2013.08.012

Fiers W, Beyaert R, Declercq W and Vandenabeele P (1999). More than one way to die: apoptosis, necrosis and reactive oxygen damage. Ontogeny, 18: 7719-7730. DOI: https://doi.org/10.1038/sj.onc.1203249

Fischer B, Künzel W, Kleinstein J and Gips H (1992). Oxygen tension in follicular fluid falls with follicle maturation. European Journal of Obstetrics Gynecology and Reproductive Biology, 43: 39-43. DOI: 10.1016/0028-2243(92)90241-p

Gasparrini B (2002). In vitro embryo production in buffalo species: State of the art. Theriogenology, 57(1):237-256. DOI: 10.1016/S0093$\underline{691 X(01) 00669-0}$

Gasparrini B (2007). In vivo embryo production in buffalo: current situation and future perspectives. Italian Journal of Animal Science, 92-101. DOI: https://doi.org/10.4081/ijas.2007.s2.92 
Goszczynski ED, Cheng H, Peyras SED, Medrano JF, Wu J and Ross PJ (2018). In vitro breeding: application of embryonic stem

cells to animal production. Biology of Reproduction, 100(4): 885-895. DOI: https://doi.org/10.1093/biolre/ioy256

Goto Y, Noda Y, Mori T and Nakano M (1993). Increased generation of reactive oxygen species in embryos cultured in vitro. Free Radical Biology and Medicine, 15: 69- 75. DOI: https://doi.org/10.1016/0891-5849(93)90126-f

Hafez YM (2015). Assisted Reproductive Technologies in Farm Animals. ICMALPS Alexandria University, Egypt, 91 -118.

He L, He T, Farrar S, Ji L, Liu T and Ma X (2017). Antioxidants maintain cellular redox homeostasis by elimination of reactive oxygen species. Cellular Physiology and Biochemistry, 44:532-553. DOI: https://doi.org/10.1159/000485089

Kala M, Shaikh MV and Nivsarkar M (2016). Equilibrium between anti-oxidants and reactive oxygen species: a requisite for oocyte development and maturation. Reproductive Medicine and Biology, 16: 28-35. DOI: https://doi.org/10.1002/rmb2.12013

Karagenc L, Sertkaya Z, Ciray N, Ulug U and Bahçe CM (2004). Impact of oxygen concentration on embryonic development of mouse zygotes. Reproductive Biomedicine, 4:409-417. DOI: https://doi.org/10.1016/S1472-6483(10)61276-X

Kitagawa Y, Suzuki K, Yoneda A and Watanabe T (2004). Effects of oxygen concentration and antioxidants on the in vitro developmental ability, production of reactive oxygen species (ROS), and DNA fragmentation in porcine embryos. Theriogenology, 62: 1186-1197. DOI https://doi.org/10.1016/j.theriogenology.2004.01.011

Leoni GG, Rosati I, Succu S, Bogliolo L, Bebbere D, Berlinguer F, Ledda S and Naitana S (2007). A low oxygen atmosphere during IVF accelerates the kinetic of formation of in vitro produced ovine blastocysts. Reproduction in Domestic Animals, 42: 299-304. DOI https://doi.org/10.1111/j.1439-0531.2006.00783

Liu Z and Foot RH (1995). Development of bovine embryos in KSOM with added superoxide dismutase and taurine and with five and twenty percent $\mathrm{O}_{2}$. Biology of Reproduction, 53(4):786-790. DOI: https://doi.org/10.1095/biolreprod53.4.786

Lopes AS, Lane M and Thompson JG (2010). Oxygen consumption and ROS production are increased at the time of fertilization and cell cleavage in bovine zygotes. Human Reproduction, 25: 2762-2773. DOI: https://doi.org/10.1093/humrep/deq221

Ma YY, Chen HW and Tzeng CR (2017). Low oxygen tension increases mitochondrial membrane potential and enhances expression of antioxidant genes and implantation protein of mouse blastocyst cultured in vitro. Journal of Ovarian Research, $10(1): 47$. DOI: https://doi.org/10.1186/s13048-017-0344-1.

Manjunatha BM, Gupta PS, Devaraj M, Revonda JP and Nandi S (2007). Selection of developmentally competent buffalo oocytes by brilliant cresyl blue staining before IVM. Theriogenology, 68(9):1299-1304. DOI: https://doi.org/10.1016/j.theriogenology.2007.08.031

Marsico TV, CamargoJD, Valente RS and Sudano MJ (2019). Embryo competence and cryosurvival: Molecular and cellular features. Journal of Animal Reproduction, 16(3): 423-439. DOI: https://doi.org/10.21451/1984-3143-AR2019-0072

Opiela J, Katska-Ksiazkiewicz L, Lipiński D, Słomski R, Bzowska M and Ryńska B (2008). Interactions among activity of glucose-6-phosphate dehydrogenase in immature oocytes, expression of apoptosis-related genes BC-2 and Bax, and developmental competence following IVP in cattle. Theriogenology, 69: 546-555. DOI: https://doi.org/10.1016/j.theriogenology.2007.11.001

Orsi NM and Leese HJ (2001). Protection against reactive oxygen species during mouse preimplantation embryo development: role of EDTA, oxygen tension, catalase, superoxide dismutase and pyruvate. Molecular Reproduction and Development, 59: 44-53. DOI: https://doi.org/10.1002/mrd.1006

Oyamada T and Fukui Y (2004). Oxygen tension and medium supplements for in vitro maturation of bovine oocytes cultured individually in a chemically defined medium. Journal of Reproduction and Development, 50:107-117.DOI: https://doi.org/10.1262/jrd.50.107

Pawlak P, Warzych E, Chabowska A and Lechnia D (2014). Differences in cytoplasmic maturation between the BCB+ and control porcine oocytes do not justify application of the BCB test for a standard IVM protocol. Reproduction and Development, 60 (1): 28-36. DOI https://doi.org/10.1262/jrd.2013-092

Reader KL, Stanton JL and Juengel JL (2017). The role of oocyte organelles in determining developmental competence. Biology (Basel), 6(3): 35. DOI: https://doi.org/10.3390/biology6030035

Rinaudo PF, Giritharan G, Talbi S, Dobson AT and Schultz RM (2006). Effects of oxygen tension on gene expression in preimplantation mouse embryos. Fertility and Sterility, 86: 1252-1265. DOI: https://doi.org/10.1016/j.fertnstert.2006.05.017

Rizos D, Ward F, Duffy P, Boland MP and Lonergan P (2002). Consequences of bovine oocyte maturation, fertilization or early embryo development in vitro versus in vivo: implications for blastocyst yield and blastocyst quality. Molocular Reproduction and Development, 61:234-248. DOI https://doi.org/10.1002/mrd.1153

Rodríguez-González E, López-Bejar M, Izquierdo D and Paramio MT (2003). Developmental competence of prepubertal goat oocytes selected with brilliant cresyl blue and matured with cysteamine supplementation. Reproduction Nutration Development, 43(2):179-187.DOI https://doi.org/10.1051/rnd:2003012

Sasaki H, Hamatani T, Kamijo S, Iwai M, Kobanawa M, Ogawa S, Miyado K and Tanaka M (2019). Impact of oxidative stress on age associated decline in oocyte developmental competence. $\quad$ Frontiers $\quad$ in Endocrinology, $\quad$ 22: $10: \quad 811 . \quad$ DOI: https://doi.org/10.3389/fendo.2019.00811.

Shkolnik K, Tadmor A, Ben-Dor S, Nevo N, Galiani D and Dekel N (2011). Reactive oxygen species are indispensable in ovulation. Proceedings of the National Academy of Sciences of the United States of America, 108(4): 1462-1467. DOI: https://doi.org/10.1073/pnas.1017213108

Simopoulou M, Sfakianoudis K, Rapani A, Giannelou P, Anifandis G, Bolaris S, Pantou A, Lambropoulou M, Pappas A, Deligeoroglou E, Pantos K and Koutsilieris M (2018). Considerations regarding embryo culture conditions: From media to epigenetics. In Vivo, 32(3):451-460. doi:10.21873/invivo.11261

Silva DS, Rodriguez P, Galuppo A, Arruda NS and Rodrigues JL (2013). Selection of bovine oocytes by brilliant cresyl blue staining: effect on meiosis progression, organelle distribution and embryo development. Zygote, 21(3): 250-2555. DOI: https://doi.org/10.1017/S0967199411000487

Stinshoff H, Wilkening S, Hanstedt A, Brüning K and Wrenzycki C (2011). Cryopreservation affects the quality of in vitro produced bovine embryos at the molecular level. Theriogenology, 76: 1433-1441.DOI: https://doi.org/10.1016/j.theriogenology.2011.06.013

Takahashi M (2012). Oxidative stress and redox regulation on in vitro development of mammalian embryos. Journal of Reproduction and Development, 58(1):1-9. DOI: https://doi.org/10.1007/s12522-013-0170-0

Takahashi M, Keicho K, Takahashi H, Ogawa H, Schultz RM and Okano A (2000). Effect of oxidative stress on development and DNA damage in in vitro cultured bovine embryos by comet assay. Theriogenology, 54: 137-145.

DOI: https://doi.org/10.1016/s0093-691x(00)00332-0

Thompson JG, Simpson AC, Pugh PA, Donnelly PE and Tervit HR (1990). Effect of oxygen concentration on in-vitro development of preimplantation sheep and cattle embryos. Journal of Reproduction and Fertility, 89(2):573-578. 
Torres-Osorio V, Urrego R, Echeverri-Zuluaga JJ and López-Herrera A (2019). Oxidative stress and antioxidant use during in vitro mammalian embryo production. Journal of Revista Mexicana de Ciencias Pecuarias, 10(2):433-459.

DOI: https://doi.org/ 10.22319/ rmcp. v10i2. 4652

Wang L, Lin J, Huang J, Wang J, ZhaoY and Chen T (2012). Selection of ovine oocytes by brilliant cresyl blue staining. Journal of Biomedicine and Biotechnology, 1: 1-7. DOI: https://doi.org/10.1155/2012/161372

Wongsrikeao P, Otoi T, Yamasaki H, Agung B, Taniguchi Mm, Naoi H, Shimizu R and Nagai T (2006). Effects of single and double exposure to brilliant cresyl blue on the selection of porcine oocytes for in vitro production of embryos. Theriogenology, 66: 366-372. DOI: https://doi.org/10.1016/j.theriogenology.2005.12.001 